\title{
Developing Land Information Management Systems for County Governments in Kenya
}

\author{
Robert Wayumba ${ }^{1}$ \\ ${ }^{\text {I}}$ (School of Surveying and Geospatial Sciences/ Technical University of Kenya)
}

\begin{abstract}
There is a need to develop Land Information Management Systems (LIMS) for county governments in Kenya. In the year 2010, the Republic of Kenya promulgated a new constitution, which led to the introduction of forty seven county governments. Each of the counties is supposed to develop a LIMS. In this regard, a LIMS can be described as a Geographic Information System that is dedicated to cadastral maps and land registry records. An effective LIMS can contribute towards improving: land tenure security, real estate markets, access to credit, taxation and dispute resolution. The LIMS should also remedy the problem of paper land records, which are susceptible to wear and tear, can get lost, may be difficult to retrieve and often difficult to integrate with other systems. The problem statement for this paper is that it is not clear how the LIMS should be developed for the counties. This paper employs grounded theory methodology to explain why and how the LIMS may be developed. The results are categorized into: human resource development, institutional arrangements and, design and implementation of the systems. The hope is that this paper will contribute towards implementation of LIMS not only in Kenya but also in other developing countries.
\end{abstract}

Keywords: - County Governments, Land Information Management Systems,

\section{INTRODUCTION}

There is a need to develop Land Information Management Systems (LIMS) for county governments in Kenya. In the year 2010, the Republic of Kenya promulgated a new constitution, which led to the introduction of forty seven county governments [1]. In this regard, the county governments are supposed to take up some of the functions that were held by the national government [1]. One of the roles of the county governments is to develop Geographic Information Systems (GIS) based spatial plans [2]. Part of the GIS systems should include a LIMS. A LIMS can be described as a GIS that is dedicated to cadastral maps and land registry information [3]. The problem statement for this paper is that it is not clear how the LIMS should be implemented for the newly formed county governments in Kenya.

An effective Land Information Management Systems (LIMS) can contribute towards sustainable development in a country [4]. In this regard, sustainable development can be described as the ability to use resources today without jeopardizing the ability of future generations to enjoy similar resources [4]. Due to the value of sustainability, member states of the United Nations passed the Sustainable Development Goals (SDGs) as a means of transforming our World [5]. A LIMS contributes towards sustainable development by: improving land tenure security, developing land markets, increasing access to credit, enabling taxation and reducing land disputes among others [4].

A LIMS can also improve the management and use of land records. In general, land records in most developing countries are usually in paper form. The paper records are susceptible to wear and tear, can get lost, may be difficult to retrieve and often difficult to integrate with other systems [6]. A LIMS can remedy the problems of paper land records because it has a database which can be used to secure the data, it can be queried electronically hence data retrieval is fast and it can be secured using various electronic techniques [7].

There have been various efforts to develop LIMS in Kenya. At the national level, there are two main agencies that have mandate over land ownership records, namely the Ministry of Lands and Physical Planning and the National Land Commission. Both agencies have made efforts at developing National Land Information Management Systems (NLIMS). In the ministry, an initiative known as Project of Improving Land Administration in Kenya (PILAK) has contributed towards development of NLIMS [8]. The PILAK initiative has been able to: develop a model digital archive that should be replicated nationwide, arranged paper files in a strong room, acquired enterprise document management system software and established a modern training computer Laboratory [8]. However, despite the efforts, the ministry has not yet been able to establish a fully 
functional NLIMS at national level. The National Land Commission has also attempted to develop an NLIMS [9]. The commission has developed a model for the system, which is based on the Land Administration Domain Model (LADM) and the Social Tenure Domain Model [9]. The commission has also developed Standards and Guidelines that can be used to implement the NLIMS [9]. In spite of the efforts, the commission has also not been able to develop a fully functional NLIMS at the national or county levels in Kenya.

Due to the lack of a functioning LIMS at national and county levels in Kenya, this paper attempts at explaining how a system might be developed. The author acknowledges that development of such a system is complex and requires input from varied professionals. However, an attempt is made to explain how key aspects of the system can be tackled. Thus, the main aim of this paper is to explain why and how LIMS can be developed for county governments in Kenya. The hope is that this paper will contribute towards development of LIMS, not only in Kenya but also in other developing countries.

The remaining parts of this paper are structured as follows. Part two will explain the use of grounded theory as a methodology for this paper, part three will provide the results, which are divided into human resource development, institutional arrangements and, design and implementation of the systems. Finally, part four will provide a conclusion for this paper.

\section{METHODOLOGY}

Grounded theory was selected as the main methodology for this paper. Grounded theory is a social science methodology that is used for constructing theories based on analysis of data [10]. The sources of data in this methodology includes: interviews, observations, government documents, newspaper articles, books and any other material that can shed light on the subject under investigation [11]. Developing a grounded theory has four main steps; first the researcher develops codes, then concepts, the categories and finally a theory [11].

In this research, the main sources of data were existing literature on various aspects of LIMS. Based on the existing literature, the researcher came up with three main categories of LIMS that should be considered for effective implementation of the systems. The first category is human resource development. This category emerged because without people the system cannot function. The second category was institutional arrangements. In this regard the word institutions refer to organizations. This category emerged because the systems must be hosted by organizations and may need to be accessed by various people. Finally, aspects of system development and implementation were considered from a broad perspective. This category was considered because it is what translates the system into reality.

Based on the three categories, a theory was constructed on why and how LIMS can be developed for county governments in Kenya.

\section{RESULTS}

The results are divided into three sections, namely, human resource development, institutional arrangements and, systems and development, each of which is elaborated below.

\subsection{Human Resource Development}

In order to implement LIMS at county levels, there is a need for effective human resource development. In this paper, human resource development is restricted to training of staff members. A key component of Geographic Information Systems (GIS) is people [12]. People are essential to the design and functioning of the systems. In this regard, staff members within county governments need to undergo training on various aspects of LIMS. There should be different types of training for varied types of staff members. The types of training should include: short courses for executive staff members to understand why and how to implement such as system, in-depth short courses for staff members who already have some background on such systems and who would be working with the systems on a day-to-day basis and long term courses for staff members who need thorough grounding on LIMS.

At the county governments, there are various executives who need short term training so that they can appreciate LIMS. The forty seven counties are headed by governors who are elected every five years. Each of the counties also has an elected deputy governor. The governors and deputy governors have an umbrella body known as The Council of Governors, through which they articulate their vision for prosperity in the counties 
[13]. Thus, the first level of executive training on LIMS should be provided for governors and deputy governors. Ideally, this type of training should be organized through the council of governors.

The second levels of county officials who need training on LIMS are Members of County Assemblies (MCAs) and other top level executives in the county. The MCAs are usually either elected or nominated. The roles of the MCAs include county development planning and approving of budgets [2]. Hence, they are very crucial in successful implementation of LIMS. Each county also has a head of public service and directors who head various departments [2]. Thus, another executive level training on LIMS should be offered for the MCAs and top county executives. In general, these should be very short courses, in which the officials appreciate why and how the systems can work. The training can include theoretical power point presentations, hands on session and possibly group discussions.

Short in-depth courses should also be organized for relevant technical staff in the counties. The technical staff could be people who have academic backgrounds in disciples such as geospatial engineering, also known as land surveying, physical and urban planners, land economists, land registrars, adjudication officers and staff concerned with Information and Communication Technology (ICT). These technical staff members should majorly have hands-on training on how to design implement and use the systems. The training should lead to some form of certification that can be recognized in the country.

The counties should also offer long term training for staff members on various aspects of LIMS. In this regard, the counties can sponsor some staff members to attend undergraduate or postgraduate qualifications on LIMS. Basically, there is a need for experts on aspects of land surveying and mapping, computer systems and laws related to ICT. The training can be either undertaken locally or internationally recognized institutions.

The final part of training is on the details of what should be covered in the training. In general, a LIMS consists of people, software, hardware, data and methods of analysis. In order to be able to fully utilize a LIMS, staff members need to be experts in each of these aspects. Thus, the training offered to staff members should be in the form of a cross i.e. all staff should have a broad knowledge of what constitutes LIMS, but each should have in-depth knowledge in a particular discipline. This will ensure all parts of the system can work at a general and detailed level. The in-depth training which should be provided for different people should cover details of land surveying and registration, computer science and laws on ICT.

If the above types of training are offered to staff members at counties, the Republic of Kenya will have made a very big step towards introducing LIMS at county level. However, the details of the training can be reexamined depending on expert advice and discussions with other key stakeholders. The next section explains institutional arrangements that should be considered for LIMS to work.

\subsection{Institutional Arrangements}

The institutional arrangement of the LIMS may be in line with the existing land governance arrangement in Kenya. In general, land governance is described as the "rules, processes and structures through which decisions are made about the use of and control over land, the manner in which the decisions are implemented and enforced, and the way that competing interests in land are managed" [14]. A lack of clear institutional arrangement for LIMS has led to duplication of efforts. In this regard, the Ministry of Lands is attempting to develop a national system [8], similarly, the National Land Commission (NLC) is attempting to develop a NLIMS [9] and county governments are mandated to develop GIS based spatial plans which contain data similar to that of LIMS [2].In order to have a functional LIMS there is a need to adopt an institutional structure that might be acceptable at both national and county government levels. Thus, the structure of the LIMS should be guided by the Constitution and other land laws in the country. As stated in the Constitution of Kenya, Section 6 (2), the country has two levels of government that are distinct and interdependent [1]. Thus, the structure of LIMS should include the two levels of government. The structure of LIMS should also capture the main agencies that are mandated to manage land at the national and county levels. In this regard, at the national level, the two main agencies that are in charge of land are the Ministry of Lands and Physical Planning and the National Land Commission [8,9]. The county governments also have specific departments that are responsible for cadastral maps and land registration. Thus, the proposed institutional arrangement should have the Ministry of Lands playing an oversight and unification role at the national level and the counties developing systems within their jurisdictions. In an ideal situation, the Ministry and NLC should develop an overall system design and framework for LIMS that should be adopted by all the counties. Adoption of the same guidelines in 
all counties will ensure that the systems are interoperable at all levels. Therefore, a proposed institutional structure for the LIMS is shown in Figure 1.

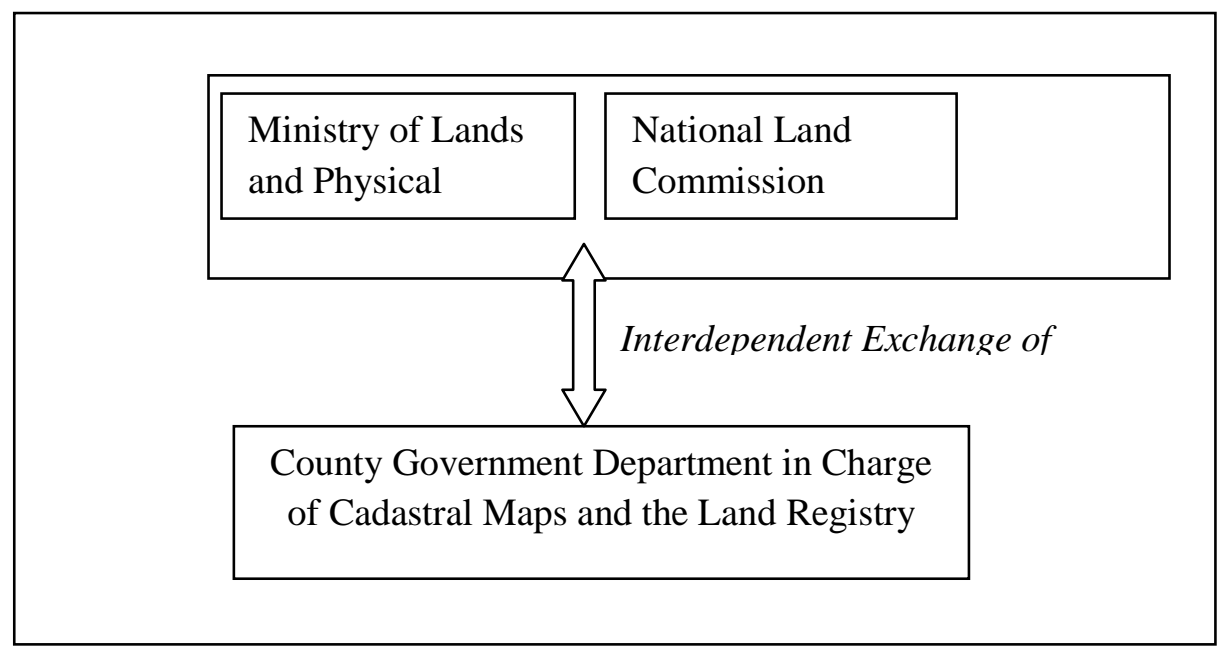

Fig. 1 shows a proposed institutional framework for county LIMS in Kenya

The proposed institutional arrangement should be expanded to include specific departments as agreed by stakeholders. In essence, the Ministry has various departments that deal with various aspects of land, such as Survey and Mapping, Physical Planning, Land Adjudication and others [15]. The Ministry should designate specific officers who are in charge of matters related to LIMS, and who can ensure appropriate sharing of data with NLC and the counties. The NLC has a specific directorate that is in charge of NLIMS [9]. In addition, the commission has a directorate of ICT, which supports the development of NLIMS [9]. Thus, at the national level, the Ministry and NLC should agree on how they work together to develop the systems for the benefit of the country. At the county level, different counties have labeled the departments that deal with cadastral maps and land registers differently. In this regard, there is a need for unification on how the departments are named. In addition, the counties should specify not only counties, but individual staff members who are supposed to develop the LIMS. The individuals should include experts in Land Surveying also known as Geospatial Engineering, ICT and Lawyers who understand ICT laws. These individuals should work with the county government authorities, the Ministry and NLC to develop fully functional LIMS that can contribute to economic growth in the counties. Financial aspects of the LIMS should also be embedded in the institutional arrangements. There should be clarity on how finances will be obtained and managed for developing and implementing the systems, it should also be clear how funding can be raised from external sources such as donor agencies and how resources obtained from the systems will be utilized. It should be clear how much of the funding can be obtained from the national government, the county governments and donor agencies. In order to develop a rigid system of financing, the stakeholders should come together and agree on a way forward. The financial aspects can be guided by existing international frameworks such as the "Costing and Financing of Land Administration Services (CoFLAS) in Developing Countries" [16].In general, CoFLAS is a tool that is intended to support "Land sector staff in preparing proposals for LAS reform; Policy makers in the land sector in assessing such proposals and in making a case for support within government and from development partners; and Key government agencies such as finance and development partners in reviewing LAS reform proposals and ensuring that such proposals provide value for money" [16]. In essence, the financial aspects of LIMS should be managed properly to avoid failure. This section has provided a brief synopsis of institutional arrangements of LIMS, which requires further analysis. The next section will provide a possible approach to the system design and implementation.

\subsection{System Design and Implementation}

This section explains a possible system design and implementation for the county governments in Kenya. In this paper, system design is described as the process of defining the architecture, interface, modules and data requirements among others [17]. The design process assists to decide how the system will work in terms of software, hardware, interface, internet and databases among others [18]. Implementation refers to how 
the designed system is made operational. The design process also includes how the system will be secured, which is paramount for land related data.

The system design and implementation involves two main processes, namely, user needs assessment and the design itself [19]. The user needs assessment can be used to determine: work flows, data requirements, required software and hardware solutions and an implementation schedule among others [18]. The design itself will include: system configuration alternatives, system design components, system load analysis, hardware sizing and an implementation schedule [18].

In terms of LIMS, the user needs assessment should include a description of land records and associated work flows. In Kenya, there are two main types of cadastral maps, namely, deed plans and registry index maps [20]. There are multiple workflows that are related to the development of the maps, such as survey and mapping, physical planning, land adjudication and in some cases land consolidation among others [21]. In the registry, data is stored concerning ownership of different interests in land, such as freehold title deeds, leasehold titles, sectional property ownership and group ranches among others. The registry also contains information on proprietors, encumbrances and charges on land [22]. Aspects of the coordinate systems and map projections used for maps should also be considered. The coordinate systems used for mapping in Kenya include different components, which should be taken care off in the system. In general, the main geodetic system in the country is based on the 1960 Arc Datum and the Universal Transverse Mercator coordinate system [23]. Two reference ellipsoids have also been used in the country, namely Clarke 1858 and Clarke 1880. In terms of cadastral maps, data has been produced in many different systems, the main ones being, the cassini-soldner coordinate system, The East African war system and The Universal Transverse Mercator [24]. Therefore, in order to develop a robust LIMS, the different systems should be resolved and possibly be converted to an international system such as The World Geodetic Systems (WGS) 1984.

The System design should either adopt an existing model or develop a completely new one that suites the country. There are various models that have been developed as a means of capturing land administration data in computers. One model is referred to as the Land Administration Domain Model (LADM), which is an international model that describes how rights, restrictions and responsibilities related to land [25]. Another one is the Social Tenure Domain Model (STDM), which in addition to aspects of LADM, attempts to include social aspects of land, such as informal and customary tenure [26]. Despite the existence of the models, there might be a need to develop totally new models for Kenya. In general, the models have to a large extent been developed from a "Western" perspective which often assumes exclusive rights to land. Thus, the LADM, may not be appropriate for the counties. The types of land records and workflows used in Kenya may also not fir directly into the existing models. Thus, there is a need for local experts to investigate the existing models, and if necessary develop new ones. The design of the models can be done using standard industry languages such as the Unified Modelling Language (UML), which have been recommended for cadastres [27].

The computerized aspects of the LIMS should also be designed and implemented properly. Ideally, the system will include the use of appropriate Geographic Information Systems Software, Database systems, hardware and internet systems among others [19]. The designed system should have linkages between county governments and the national systems. In addition, the system should have linkages to other government agencies such as the Kenya Revenue Authority (KRA), which is in charge of tax collection. The system may also be connected to banks and other financial institutions which offer loans. The system should also be connected to other government agencies such as the Ministry of Roads, Ministry of Water and Electricity companies. The connection with other agencies will enable efficient data sharing and reduce conflicts between different forms of land use and parcel boundaries. In this regard, Figure 2 shows a proposed architecture. However, the exact configuration of the system should be decided after consultation with stakeholders. 


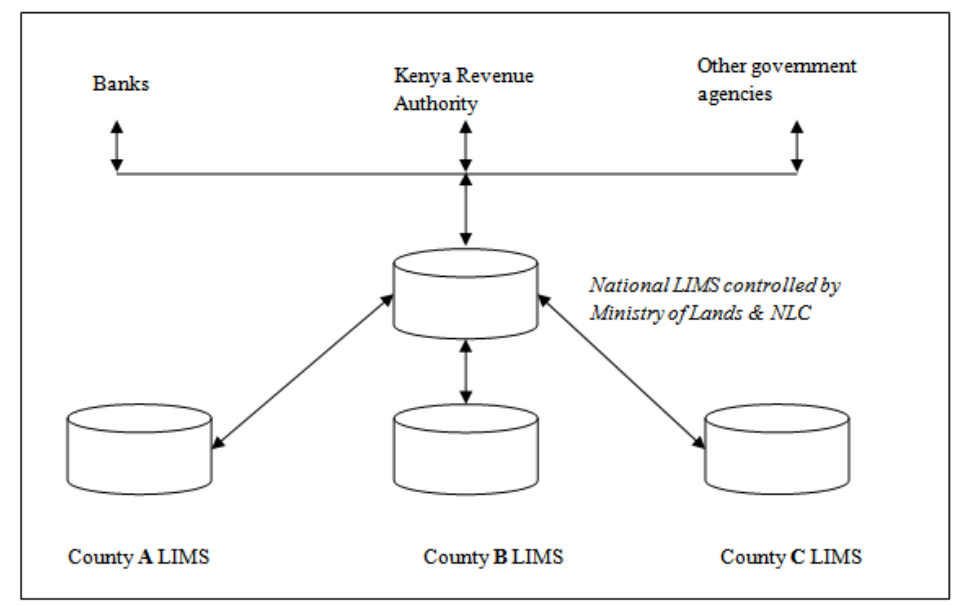

Fig. 2 shows a general architecture of how county LIMS should be connected with other agencies

The system design should also include details on user access, internal database arrangements, internet connectivity, workflows by county staff members and security among others. In general, the system should have a web interface through which the public can make requests and payments. The web should be connected to database systems in the county offices by appropriate software that can communicate between the web pages and the databases. In the county offices, there should be server side software and desktop software for the systems. In this case, the server side software would manage data within the main servers and the desktop software would be used by staff members for authoring, editing or managing the records in the server [28]. In addition, the systems must have tamper proof security systems. The security system should include firewalls, passwords and any other necessary mechanism, such as secured rooms. A general architecture of how the system should be configured is shown in Figure 3. Again, the exact configuration should be decided after extensive consultations with computer and Geographic Information Systems experts.

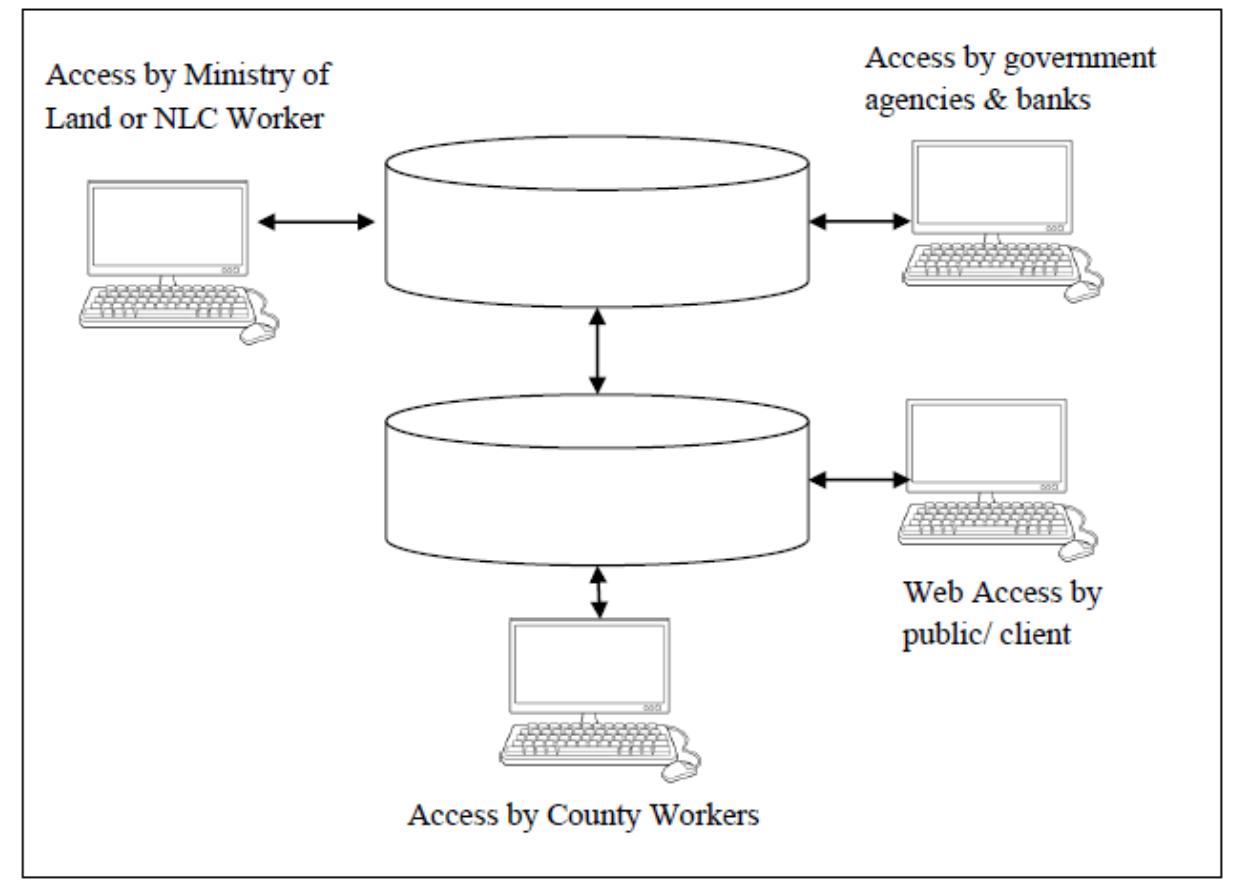

Figure 3 shows a simple configuration of the LIMS which should be connected through secure networks

System implementation should be scheduled and phased. In system design, it is important to have a scheduled implementation process [19]. There is a need to determine which aspects of the system are to be implemented first, and tested before further components are connected. For example, the county databases can be developed first and tested in-house before connections are made with the national systems. After the county and national systems are effectively integrated, the public can then be given access through secure systems, in 
which they may be required to pay for some services. Ideally, in the first few years, the public may have to make manual applications to the county officials, who will then make digital requests to the system. After the system is proven to be robust enough, it can be open to the public and other government agencies. Due to the sensitivity of land records, it is better to be slow and sure in the implementation, as opposed to rushing to launch a system that is not ready. The next section will provide a conclusion for this paper.

\section{CONCLUSION}

This paper has explained why and how Land Information Management Systems (LIMS) might be introduced for county governments in Kenya. As stated earlier, county governments were introduced by a new constitution that was promulgated in Kenya in 2010. This paper has explained why and how, aspects of LIMS, namely, human resource development, institutional arrangements and, design and implementation, can be handled during development. As stated in the beginning, there is no clear guideline on how the county LIMS should be developed in Kenya. Thus, this paper has provided a first step on how the county LIMS can be developed. The paper has some limitations, because in order to develop such systems, there is a need for consultations with different types of experts and stakeholders. In this regard, it is recommended that this paper can act as a first step for determining how detailed consultations can be made and how the systems can be designed and implemented in Kenya. Ideally, such systems can contribute towards sustainable development in a county. The main hope is that this paper will contribute towards development of effective LIMS not only for counties in Kenya, but also in other developing countries.

\section{REFERENCES}

[1] The Constitution of Kenya, 2010, Government Printer. Nairobi, Kenya.

[2] The County Governments Act, 2012, Government Printer. Nairobi, Kenya.

[3] Wade, T. and Sommer, S., 2006. A to Z GIS, An illustrated dictionary of geographic information systems. Esri Press.

[4] Williamson, I., Enemark, S., Wallace, J. and Rajabifard, A., 2010. Land administration for sustainable development (p. 487). Redlands, CA: ESRI Press Academic.

[5] United Nations. 2015. Transforming Our World: The 2030 Agenda for Sustainable Development. https://sustainabledevelopment.un.org/content/documents/21252030\%20Agenda\%20for\%20Sustainable $\% 20$ Development\%20web.pdf

[6] Dale, P.F. and McLaughlin, J.D., 1988. Land information management: an introduction with special reference to cadastral problems in Third World countries.

[7] MacDonald, A., 2001. Building a geodatabase. Redlands: ESRI.

[8] Nyongeza, L., 2012. GIS-Based national land information management system (NLIMS). In FIG Working Week (pp. 6-10).

https://www.fig.net/resources/proceedings/fig_proceedings/fig2012/papers/ts07b/TS07B_uthas_nyongesa 6218.pdf

[9] Kuria, D., Kasaine, A., Khalif, A., and Kinoti, S., 2016. Developing A National Land Information Management System - The Kenyan Strategy. World Bank Conference On Land And Poverty" The World Bank - Washington Dc, March 14-18, 2016.

file:///C:/Users/Robert/Downloads/Kuria-136-136_paper\%20(2).pdf

[10] Strauss, A. and Corbin, J., 1994. Grounded theory methodology. Handbook of qualitative research, 17, pp.273-85.

[11] Charmaz, K., 2011. Grounded theory methods in social justice research. The Sage handbook of qualitative research, 4, pp.359-380.

[12] Goodchild, M.F., 2009. Geographic information system. In Encyclopedia of Database Systems (pp. 12311236). Springer US.

[13] The Council of Governors Website, Kenya., 2017. https://cog.go.ke/index.php/newsmed/cog-newsletters

[14] Palmer, D., Fricska, S. and Wehrmann, B., 2009. Towards improved land governance. UN-HABITAT.

[15] Ministry of Lands and Physical Planning Website., 2017. http://www.ardhi.go.ke/?page_id=6.

[16] Burns, A., Fairlie, K. and Haile, S., 2015. Costing and financing of land administration services.

[17] Bentley, L.D., Dittman, K.C. and Whitten, J.L., 2004. Systems analysis and design methods. Purdue University.

[18] Dennis, A., Wixom, B.H. and Roth, R.M., 2008. Systems analysis and design. John wiley \& sons.

[19] Peters, D., 2003. System Design Strategies. An ESRI White Paper. 
http://www.esri.com/library/whitepapers/pdfs/sysdesig.pdf

[20] Siriba, D.N., Voß, W. and Mulaku, G.C., 2011. The Kenyan Cadastre and Modern Land Administration. Zeitschrift fur Vermessungswesen, 136, pp.177-186.

[21] Wayumba, G.O., 2013. An evaluation of the cadastral system in Kenya and a strategy for its modernization (Doctoral dissertation, University of Nairobi).

[22] Wanjala, S.C., 2000. Essays on land law: the reform debate in Kenya.

[23] Aduol, F., WO,(2006): From Rope Stretchers to E-Mapping. The Story of the Discipline of Surveying, Inaugural Lecture, University of Nairobi, pg, pp.107-108.

[24] Mugnier, C., 2013. Geodetic Report of Kenya. https://www.researchgate.net/publication/258509444_Geodetic_Report_of_Kenya

[25] Lemmen, C., Van Oosterom, P. and Bennett, R., 2015. The Land Administration Domain Model. Land Use Policy, 49, pp.535-545.

[26] Lemmen, C., Augustinus, C., van Oosterom, P. and van der Molen, P., 2007, May. The social tenure domain model: design of a first draft model. In FIG Working week.

[27] Tuladhar, A.M., 2002, October. Why is Unified Modeling Language (UML) for Cadastral Systems?. In COST Workshop 'Towards a Cadastral Core Domain Model', Delft, The Netherlands.

[28] Zeiler, M., 1999. Modeling our world: the ESRI guide to geodatabase design. ESRI, Inc.. 